\title{
A practical application of a children's disaster prevention education program in the Philippines
}

\author{
M. Yasuda, C. J. Yi, R. Nouchi, A. Suppasri \& F. Imamura \\ International Research Institute of Disaster Science, \\ Tohoku University, Japan
}

\begin{abstract}
During large-scale natural disasters, vulnerable groups, such as children and senior citizens, frequently constitute a high percentage of the deaths and/or injuries that occur. To survive these disasters and recover adequately, it is imperative that organizations train for and develop disaster prevention initiatives. The International Research Institute of Disaster Science (IRIDeS) of Tohoku University deployed a disaster education team to enhance local community resilience and reduce the impact of disasters among elementary students in the Philippines after the destruction of Typhoon Haiyan. This educational program consisted of several workshops for children in the higher grade levels of elementary school due to their strong backgrounds and interest in science. We conducted disaster education workshops at four elementary schools in areas affected by Typhoon Haiyan. Approximately 200 students participated in these disaster education workshops and practical drills. After the lectures, positive attitudes about disaster education at the three schools increased. Because largescale disasters can be accompanied by potentially diminished government assistance, this educational program seeks to improve disaster-related selfresiliency through the development of survival capabilities.

Keywords: practical education, disaster adaptation, decision making, evacuation risk communication.
\end{abstract}

\section{Introduction}

After the great tsunami that caused many deaths in Japan [1], Typhoon Haiyan formed near Truk Lagoon at approximately 9 A.M. on November 4th, 2013, and 
struck the central Philippines early on the morning of November 8th, 2013 [2, 3]. The Philippine Atmospheric Geophysical and Astronomical Services Administration (PAGASA) announced their Severe Weather Bulletin \#3, warning that the storm surges might reach up to 7-meters in wave height in the coastal areas of Eastern Samar, Samar, Leyte and Southern Leyte in Visayas [4]. The National Disaster Risk Reduction and Management Council (NDRRMC) issued an alarm and suggested that residents evacuate to nearby evacuation centers [5]. Although residents evacuated to their designated evacuation sites, these sites were located in places that were at risk from storm surges. The number of casualties and missing people after the storm officially stood at 2,603 in Tacloban, 1,101 in Palo and 859 in Tanauan (as of February 25th, 2014), according to the information provided by each municipality [4]. In countries where natural disasters occur often, such as Japan and the Philippines, it is recommended that communities have 'hard' measures in place to save lives and assets from the risks of these hazards. However, in assessing the present state of the country and its existing disaster response measures, this type of terrible tragedy could occur again if the Filipino government does not take proactive actions. There are two major types of natural disaster risk reduction processes, termed hard measures (structural measures) and soft measures (non-structural measures [6]). Fig. 1 shows the overview of the coastal areas' policy guidelines, which describe measures and approaches to enhance safety in both structural and non-structural aspects. Soft measures for disaster risk reduction could enhance

MLIT Marine/Coastal Area Policy Guideline Overview

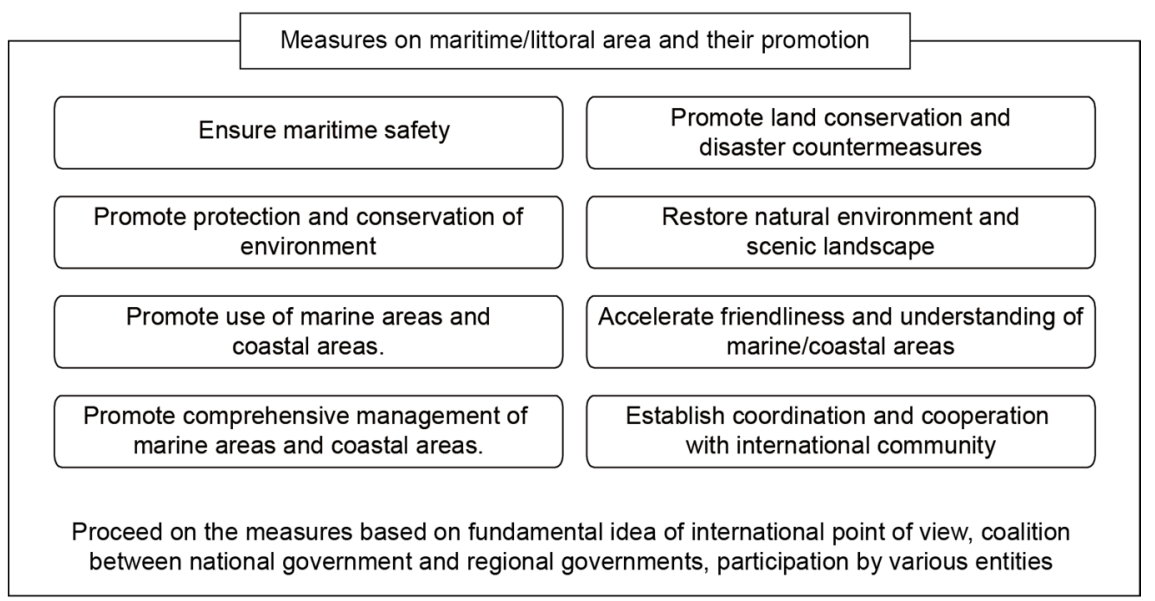

Proceed on the measures based on fundamental idea of international point of view, coalition between national government and regional governments, participation by various entities

System for promotion of the measures

Figure 1: Pamphlets used to teach maritime/coastal area safety and resilience by The Ministry of Land, Infrastructure, Transport and Tourism of Japan (MLIT). 
the community through improvements in disaster-risk reduction education, public service, recovery capabilities of the community, risk communication and so on. Therefore, soft disaster-risk reduction measurement can be interpreted as an enhancement to disaster resilience through disaster-prevention educational programs, as has been proposed by Yasuda et al. [7]. The International Research Institute of Disaster Science (IRIDeS) of Tohoku University deployed a disastereducation team to lead a special in-class workshop and on-site evacuation drill with elementary students in the Philippines after Typhoon Haiyan. Previous investigative reports from IRIDeS [4] addressed a systemic failure in the country's existing disaster response efforts, primarily pointing out the absence of elementary schools that practice evacuation procedures or provide disaster education. This educational program was designed utilizing IRIDeS's engineering/scientific background for elementary students in the higher grades. These disaster-prevention education workshops were implemented at four elementary schools in Haiyan-affected areas in the Philippines: Tacloban, Palo and Tanauan, and Leyte, between August 27th and 29th, 2014. Approximately 218 students participated in total.

\section{Evacuation education in elementary schools}

Schools were chosen for disaster education and drills based on the outcomes of an investigation performed in May, 2014 that examined evacuation routes and assessed on-site evacuation drills and geographical proximity to nearby high land or hills. The aims of these educational activities were to improve recognition of and provide appropriate knowledge about disasters and their responses. The program was divided into two categories: in-class lectures and on-site evacuation drills. In-class lectures provided children with explanations of the mechanisms behind the formation of typhoons and the destructive power of storm surges in an easy-to-understand format that utilized visual media such as animations and comparative experiment videos. Gensai Pockets were utilized during the in-class education segment. The Gensai Pocket is a tablet that provides tips for evacuation preparedness, such as carrying food supplies, lights, and whistles. Experiences during the Great East Japan Earthquake and Tsunami and Typhoon Haiyan were expressed in the pocket. The Gensai Pocket has been used in disaster reduction educational workshops in Japan, Hawaii, and Thailand, and one was given to each student so they could share what they had learned with their family and friends. If the school was located beside a hill or near high land, an evacuation drill was implemented. A total of 55 students from San Juanquin Elementary School in Palo, 58 students from Bacagay Elementary School in Tacloban and 53 students from Cabuynan Elementary School and 52 students from Bisilig Elementary School in Tanauan participated in the program. Among the four schools, on-site evacuation drills were implemented in Cabuynan and Bisilig Elementary Schools due to their proximity to a hill or higher ground. Questionnaires consisting of the same questions were distributed before and after the in-class lecture and on-site evacuation drills. The purpose of these questionnaires was to measure changes in the students' understanding of disaster 
awareness and preparedness. In addition, we used these questionnaires to verify the effectiveness of this disaster education activity.

\subsection{In-class education}

The in-class lecture was conducted in English and then translated into the local language, Warai-warai. The lecture was followed by an explanation of what measures could be used to save lives and provided concrete examples of evacuation procedures, such as leaving the seaside/river areas and evacuating to higher ground. Other examples of evacuation procedures included remaining inside sturdy concrete buildings if available, staying away from windows evacuating to a mountain or hill and grabbing branches of a tree if there are no buildings around. In-class lectures consisted of three activity categories to hold students' attention: videos, learning disaster types and their responses using Gensai Pockets as shown in Figure 2. A Gensai Pocket, a type of pamphlet that contains explanations of different disaster types and relevant responses is shown in fig. 2(a). Exercises using enlarged maps displaying satellite imagery of the school area are shown in fig. 2(b). The tablet was designed to function as a game, allowing the students to interact with its information. Google image maps, which were enlarged and printed out for the demonstrations, proved effective in spatially orienting the students and their neighbors. Students marked their own houses and matched their image maps with the printed map. This was then followed by a discussion period in which students were given time to find the closest evacuation location on the Google image map and then indicated these locations with a pin. This map was then overlaid with a plastic sheet that outlined the inundation boundaries of Typhoon Haiyan to determine whether their chosen location was safe. Students began to realize whether their houses and evacuation locations were safe from natural hazards. This exercise was a new experience for both teachers and students in the school, and it contributed to an improved understanding of the local area.

\subsection{Evacuation drill}

Two elementary schools in Tanauan were selected due to their proximity to a hill or higher ground. Cabuynan Elementary School is located 640 meters from the coast, with higher land to the west of the school. Bisilig Elementary School is located beside the beach, with steep hills located only two to three minutes walking distance from the school. The area was inundated by a 4.4 meter storm surge [8]. High land is a key factor in surviving storm surges and tsunamis. A maximum eight-meter storm surge was associated with Typhoon Haiyan, and it caused severe damage to both schools. The challenge for students was following the evacuation route identified on the Google Earth map in the earlier class. Both schools' evacuation drills were given full support by the principal and teachers, who also participated. Fig. 4 shows each school's evacuation drill. The education team pre-set the safe point for Cabuynan students beyond the water-stop point (fig. 3(a)). The distance was approximately 600 meters from the school and it took approximately 15 minutes to reach the safe point. Conversely, the topology 


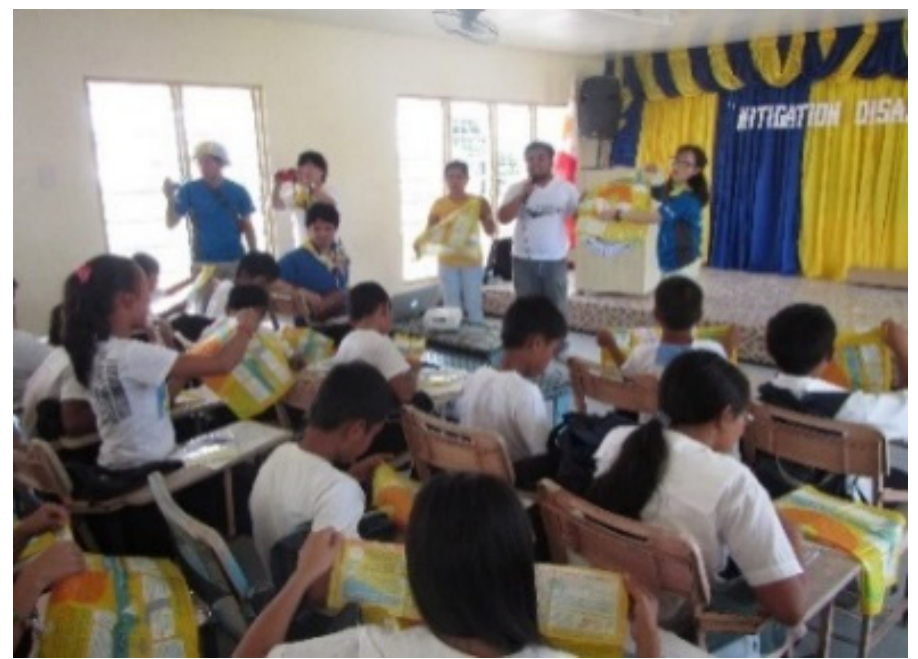

(a)

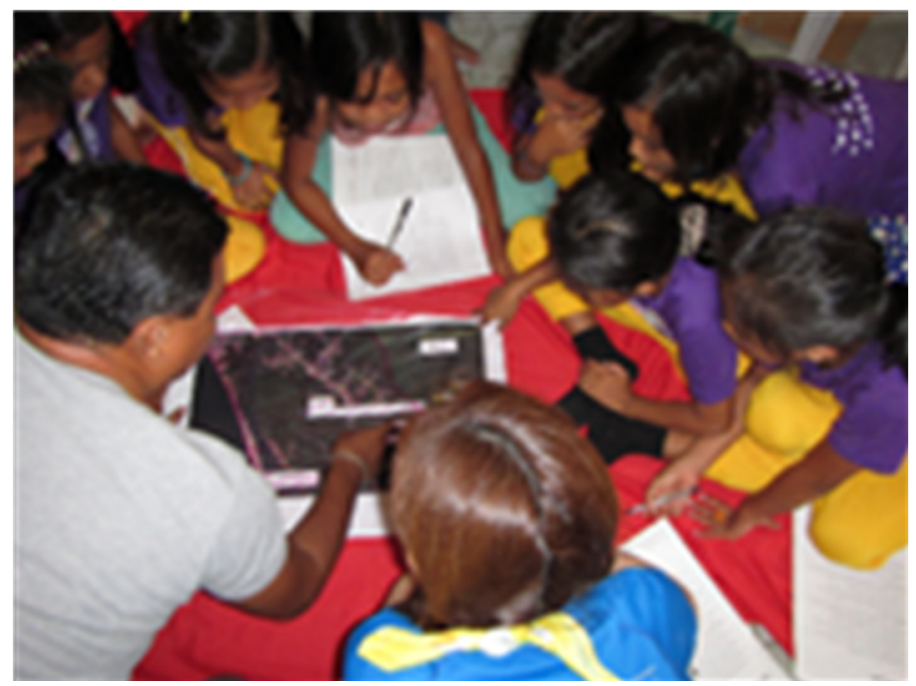

(b)

Figure 2: (a) Students receiving Gensai Pocket and (b) students identifying evacuation locations through a Google image map activity.

of Bisilig schools' evacuation hill included steep mountains and required traversing around the beach (fig. 3(b)). This hill presented difficulties in traversing the natural topology but was considered an option if either a proper evacuation route was not developed or a multipurpose facility was not built for the community. 


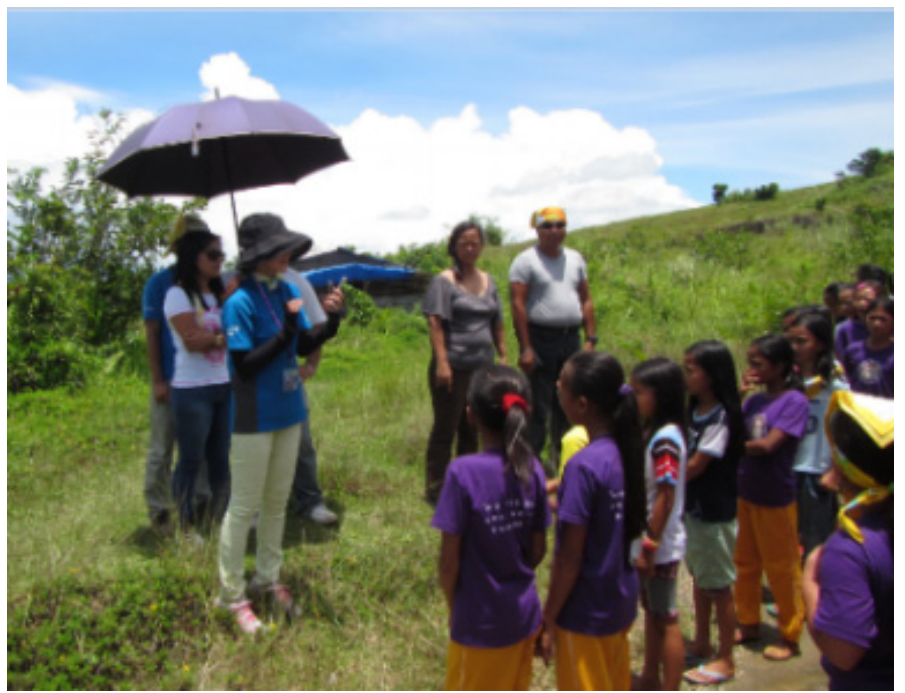

(a)

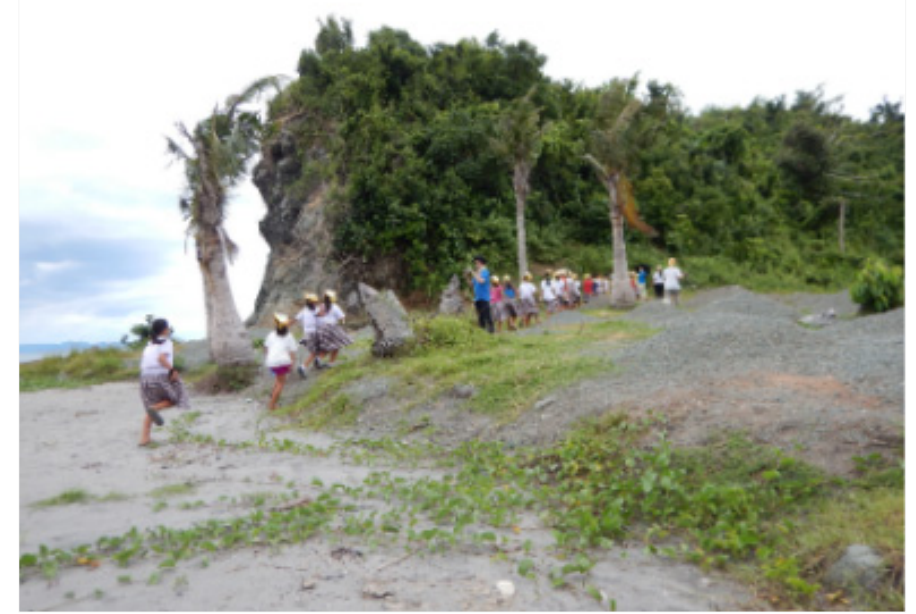

(b)

Figure 3: On-site evacuation drills: (a) Cabuynan Elementary School and (b) Bisilig Elementary School.

\section{Results}

The results of these disaster education activities led to positive changes in disaster prevention awareness. For example, on the first survey question, which focused on the impacts of typhoons, students' fear of natural disasters decreased. By understanding the mechanisms of natural hazards and discovering methods of disaster preparation, a slight change was observed. For Statement 1, 'Natural 
disasters such as typhoons, are dreadful', the percentage of children who agreed or strongly agreed increased slightly from $86.7 \%$ before the class to $87 \%$ after the class (fig. 4). However, on Statement 3, most students agreed that they or their family might be injured when natural disasters occur. The percentage of students selecting 'Disagree' also increased from $7.8 \%$ before the class to $9.1 \%$ after the class, and this change was supported by the personal experiences of students whose families did not experience any injuries during the disaster (fig. 5).

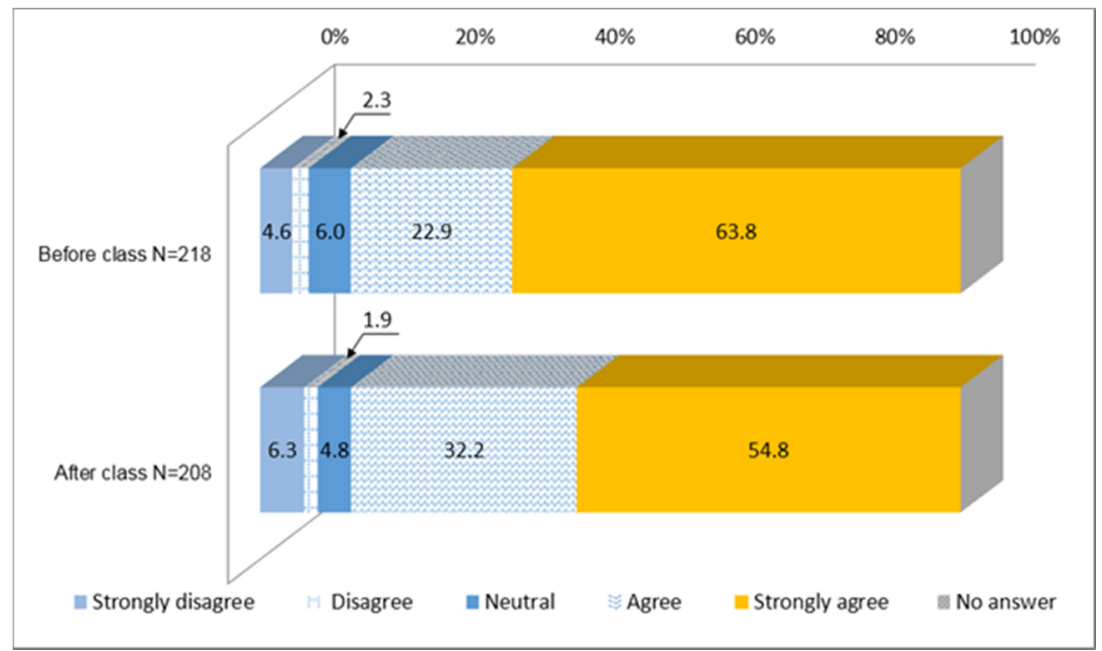

Figure 4: Responses to Statement 1: 'Natural disasters, such as typhoons, are dreadful'.

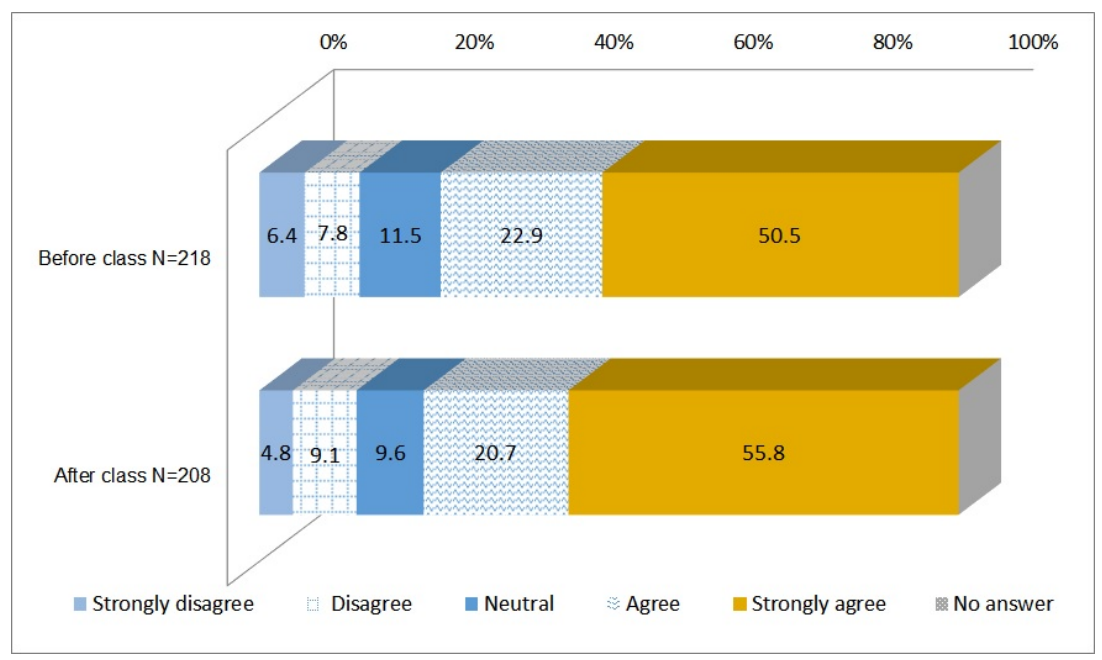

Figure 5: Responses to Statement 3: 'My family or I could be injured during a natural disaster'. 
In regards to Statement 10, 'what I have heard, seen and learned today is useful', a positive changed was observed in the percentage of students answering agree or strongly agree, which increased from $84.9 \%$ before the class to $86.1 \%$ after the class (fig. 6). Students also mentioned that they would share the contents and the experiences of the lecture with other family members.

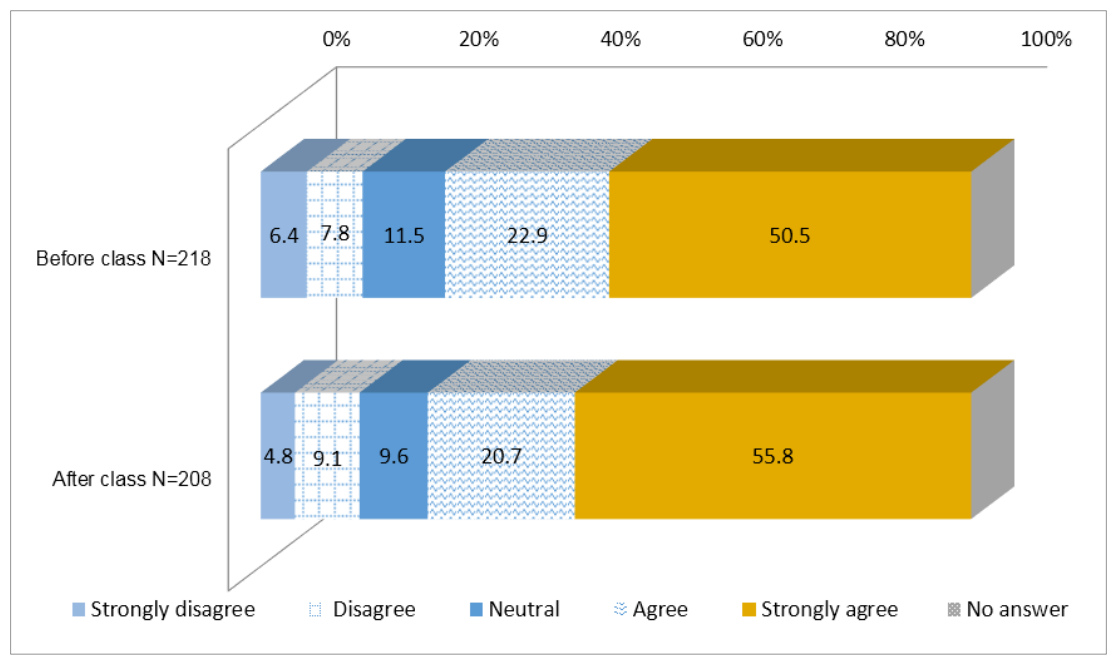

Figure 6: Responses to Statement 10: 'The things I have heard, seen, and learned today were useful'.

\section{Discussion}

The disaster-education program piloted by the IRIDeS team in areas affected by Typhoon Haiyan improved local disaster prevention and preparedness knowledge. Students' spatial recognition abilities were evaluated using on-site evacuation drills and topology maps, which were found to enhance personal and local community disaster resiliency. Although students and teachers regularly experience typhoons, the storm surge associated with Typhoon Haiyan was unprecedented. Changes in the students' mindsets were observed after evaluating pre-lecture and post-lecture surveys. As a result, a certain level of improvement in disaster awareness was demonstrated [7]. The lecture also revealed that certain storm surge-related terminology was previously unfamiliar to the students.

Financial and human resource limitations pose challenges in the ability to regularly conduct disaster-related educational activities. However, such measures can contribute to disaster prevention as education can contribute to risk reduction [6]. Through such measures, information sharing can be spread to other household members via the children, who then spearhead the formation of a disaster-resistant city when they become adult community leaders. 


\section{Acknowledgements}

This study was funded by a discretionary budget from the president of Tohoku University and the director of the International Research Institute of Disaster Science (IRIDeS), Tohoku University, and Tokio Marine \& Nichido Fire Insurance Co., Ltd.

\section{References}

[1] National Police Agency of Japan, Damage Situation and Police Countermeasures associated with 2011 Tohoku district - off the Pacific Ocean Earthquake, April 10, 2015. Available: http://www.npa.go.jp/archive /keibi/biki/higaijokyo e.pdf

[2] "Overview of Tropical Cyclones in November 2013". December 23, 2013. Retrieved December 23, 2013.

[3] NDRRMC: Situation Report Sitrep No. 4 re: Preparations for Typhoon Yolanda (Haiyan), as of 07 November 2013, 6:00 PM.

[4] International Research Institute of Disaster Science (IRIDeS), 2014, IRIDeS Fact-finding missions to Philippines (Initial Report), Tohoku University.

[5] International Research Institute of Disaster Science (IRIDeS), 2015, Second Report of IRIDeS Fact-finding mission to Philippines. Tohoku University.

[6] Ministry of Land, Infrastructure, Transport and Tourism (国土交通省), 安 心安全のためのソフト対策推進大綱 (Program for Soft Measure Policies), June 2006.

[7] Yasuda, M., Imamura, F. \& Suppasri, A. Education practice program for improving response capability to survive from natural disaster, Tohoku Research Group for Natural Disaster Science, 50:269-273, 2014.

[8] Yi, C., Yasuda, M., Suppasri, A. \& Imamura, F., Emergency mapping role in disaster risk management in case of typhoon Haiyan, Philippines. Proceeding of Society for Risk Analysis Europe Annual Meeting 2015, Masstricht, The Netherlands, 15-17 June, 2015. 